\title{
The Impact of Heat Stress on Morpho-Physiological Response and Expression of Specific Genes in the Heat Stress-Responsive Transcriptional Regulatory Network in Brassica oleracea
}

\author{
Mahdi Moradpour ${ }^{1}\left(\mathbb{D}\right.$, Siti Nor Akmar Abdullah ${ }^{1,2, * \mathbb{C}}$ and Parameswari Namasivayam ${ }^{3}$ \\ 1 Laboratory of Agronomy and Sustainable Crop Protection, Institute of Plantation Studies, \\ Universiti Putra Malaysia, Serdang 43400 UPM, Selangor, Malaysia; mahdimoradpour1@gmail.com \\ 2 Department of Agriculture Technology, Faculty of Agriculture, Universiti Putra Malaysia, \\ Serdang 43400 UPM, Selangor, Malaysia \\ 3 Department of Cell and Molecular Biology, Faculty of Biotechnology and Biomolecular Science, \\ University Putra Malaysia, Serdang 43400 UPM, Selangor, Malaysia; parameswari@upm.edu.my \\ * Correspondence: snaa@upm.edu.my; Tel.: +60-39769-4895/1099
}

Citation: Moradpour, M.; Abdullah, S.N.A.; Namasivayam, P. The Impact of Heat Stress on

Morpho-Physiological Response and Expression of Specific Genes in the

Heat Stress-Responsive

Transcriptional Regulatory Network in Brassica oleracea. Plants 2021, 10, 1064. https://doi.org/10.3390/ plants10061064

Academic Editors: Alice Pajoro and Julia Qüesta

Received: 2 February 2021

Accepted: 13 April 2021

Published: 26 May 2021

Publisher's Note: MDPI stays neutral with regard to jurisdictional claims in published maps and institutional affiliations.

Copyright: (c) 2021 by the authors. Licensee MDPI, Basel, Switzerland. This article is an open access article distributed under the terms and conditions of the Creative Commons Attribution (CC BY) license (https:/ / creativecommons.org/licenses/by/ $4.0 /)$.

\begin{abstract}
Knowledge of heat-tolerant/sensitive cultivars based on morpho-physiological indicators and an understanding of the action and interaction of different genes in the molecular network are critical for genetic improvement. To screen these indicators, the physiological performance of two different varieties of white and red cabbages (B. oleracea var. capitate $f$. alba and $f$. rubra, respectively) under heat stress (HS) and non-stress (NS) was evaluated. Cultivars that showed considerable cell membrane thermostability and less reduction in chlorophyll content with better head formation were categorized as the heat-tolerant cultivars (HTC), while those with reduction in stomatal conductance, higher reduction incurred in chlorophyll and damage to thylakoid membranes are categorized as the heat-sensitive cultivars (HSC). Expression profiling of key genes in the HS response network, including BoHSP70 (HEAT SHOCK PROTEIN 70), BoSCL13 (SCARECROW-LIKE 13) and BoDPB3-1 (transcriptional regulator DNA POLYMERASE II SUBUNIT B3-1 (DPB3-1))/NUCLEAR FACTOR Y SUBUNIT C10 (NF-YC10), were evaluated in all cultivars under HS compared to NS plants, which showed their potential as molecular indicators to differentiate HTC from HSC. Based on the results, the morphophysiological and molecular indicators are applicable to cabbage cultivars for differentiating HTC from HSC, and potential target genes for genome editing were identified for enhancing food security in the warmer regions of the world.
\end{abstract}

Keywords: heat stress; physiological measurements; morphological characteristics; DPB3-1; cabbage breeding; gene expression; transcriptional regulatory network; heat stress response; thermotolerance

\section{Introduction}

Many commonly cultivated Brassica vegetables such as cabbage, broccoli, cauliflower, kale and brussels sprouts belong to the Brassica oleracea species [1]. They are low-calorie and serve as a rich source of glucosinolates and carotenoids, as well as other vitamins, minerals and anthocyanins that are beneficial to human health [2,3]. However, Brassica vegetables are cool season crops, and most varieties are highly vulnerable to high temperature which stimulates various and often incompatible changes in plant growth, development and physiological processes which together adversely affect crop yield [4].

However, plant response to high temperature varies with the degree of temperature increment, exposure time and the type of plant. At extremely high temperatures, there will be a rapid occurrence of damage in the cells that disrupts cellular organization [5]. Heat stress (HS) has an impact on different plant processes including germination, growth and developmental and reproductive mechanisms [6]. The stability of different RNA species, proteins, membranes and cytoskeleton structures will also be adversely affected. In 
addition, the efficiency of enzymatic reactions taking part in major physiological processes will be altered, creating metabolic imbalance [7-9]. In Brassica vegetables, the negative effects of high temperature include the production of narrow leaves, leaf growth reduction, delays in heading initiation and undesired petiole-to-blade ratio enhancement (e.g., in Chinese cabbage), together contributing to lower yields and poor marketability due to the reduction in quality [10]. Cabbage head formation, which is significantly influenced by the interplay between genotype and environment [11], serves as the main phenotypic index for heat tolerance in cabbage at high temperatures [2].

The retention of protein conformation and the prevention of non-native protein aggregation are especially critical for the survival of cells under stress [12]. Reactive oxygen species (ROS)-scavenging enzymes, non-enzymatic antioxidants and heat-shock proteins (HSPs) play crucial roles in protecting cells against stress, and they are regulated through a complex transcriptional regulatory network $[2,13]$. HSPs can be divided into five different families: HSP100, HSP90, HSP70, HSP60 and HSP20. Their expression is confined to certain plant developmental stages such as seed germination, embryogenesis and maturation. They stabilize proteins and membranes that help in protein refolding, providing protection against stress by re-establishing the normal conformation of proteins [12]. The high conservation of HSP70 and HSP60 proteins is also essential for their critical role in HS response [4]. They are induced by HS and are recognized target genes of HS-responsive transcription factors [14].

An extensive transcriptional network comprising many heat stress-responsive transcription factors and the different transcriptional regulators regulates the expression of HSinducible genes [14]. TFs dehydration-responsive element binding protein 2A (DREB2A) triggers the expression of heat shock transcription factor A3 (HSFA3) as a direct target gene with a coactivator complex consisting of NF-YA2 (nuclear factor Y, subunit A2), NF-YB3 and DPB3-1/NF-YC10 (DNA polymerase II subunit B3-1 (DPB3-1))/nuclear factor y subunit c10 (NF-YC10) [15]. Prior investigations showed that DPB3-1 serves as a coactivator of DREB2A that acts only under abiotic stress. It was shown that DPB3 could be utilized to increase HS tolerance in transgenic plants without negative effects on vegetative and reproductive growth [16,17]. C3H4 RING domain-containing proteins, DRIP1 (dreb2ainteracting protein 1) and the DRIP2 were identified as DREB2A interactors that functions as E3 ubiquitin ligases mediator for DREB2A ubiquitination. Under non-stress condition (NS), double mutation of DRIP1/DRIP2 resulted in the increase in the wild-type DREB2A. DRIPs may perform as unique negative regulators involved in regulating the expression of drought-responsive genes by targeting DREB2A to 26S proteasome proteolysis [18,19].

The plant-specific GRAS transcription factor family are important plant-specific proteins, named based on the first three members: GIBBERELLICACID INSENSITIVE (GAI), REPRESSOR of GAI (RGA) and SCARECROW (SCR), which regulate diverse processes involved in plant growth, development and stress responses [20], although its function in the HS response is unclear [2]. Scarecrow-like protein 13 (SCL13), which belongs to the GRAS transcription factor family, serves as a positive regulator in the signal transduction by red light [21]. The suppression of SCL13 abated the sensitivity to red light in transgenic plants, indicating that SCL13 plays a role in the elongation of hypocotyls during de-etiolation. Gene-chip microarray gene expression studies suggested involvement of BoHsp70 and BoSCL13 in the tolerance to heat and the proper formation of cabbage heads under HS, and expression levels of BoHSP70 and BoSCL13 may perhaps be early selection markers for heat-tolerant cabbage cultivars in cabbage breeding. BoSCL13 was thus proposed as a novel candidate gene useful for the identification of HS-tolerant cabbage with potential application in crop improvement programmes [2].

In this study, we evaluated the expression level of BoDPB3-1 as a coactivator of $B o-$ $D R E B 2 A$ for the first time under HS treatments for the identification of heat-tolerant and heat-sensitive cabbage varieties. We also included BoHSP70, BoSCL13 and BoDRIP1 in our analysis as they are key genes in HS response pathways in cabbage with a potential impact on the morphological and physiological characteristics that influence thermostability 
during cabbage cultivation. Through our study, we were able to define the transcriptional network regulating HS response in cabbage to assist in future development of CRISPRbased crop modification and breeding for heat-tolerant cabbage cultivars.

\section{Results: Comparison of Different Brassica oleracea Cultivars on Heat Stress Tolerance Using Morphological and Physiological Measurements}

2.1. The Morphological Differences between Heat-Sensitive Cabbage and Heat-Tolerant Cabbage Cultivars at High Temperature

In this study, the effects of HS on the morphological characteristics of different white cabbage cultivars and one red cabbage cultivar, including head formation and mean head weight, width, length and their ratios, were measured and shown in Figure 1. Our results showed that all candidate cabbage cultivars for the morphological characteristics studies, including WCC1, WCC2, WCC3, WCC4 and RCC, were able to produce cabbage heads during NS, while WCC1 and WCC2 showed heat tolerance since they were able to produce cabbage heads during HS, whereas the WCC3, WCC4 and RCC represent the heat-sensitive phenotypes as they were not able to produce cabbage heads during HS (Figure 1a). WCC1 as a representative of heat-tolerant white cabbage cultivars, WCC4 as a representative of heat-sensitive white cabbage cultivars and RCC as a representative of heat-sensitive red cabbage cultivars were used as a positive or negative control for heat-shock stress in the gene expression studies. Furthermore, the mean weight of cabbage heads shows significant differences between white and red cabbage cultivars among cultivars under NS and HS (Figure 1b). However, among the same cultivars under the HS conditions $\left(42{ }^{\circ} \mathrm{C}\right)$, only WCC 1 and WCC2 formed cabbage heads, whereas WCC 3 and RCC did not. In addition, the mean weight of cabbage heads among the candidate cultivars ranged from $342.1 \mathrm{~g}$ for WCC1 to $257.4 \mathrm{~g}$ for WCC2. It was noted that the mean weight of the cabbage heads of WCC1 NS and HS did not differ much. Moreover, the results obtained did not show any significant difference for the mean width and length of cabbage heads in both the heat-treated and untreated plants.

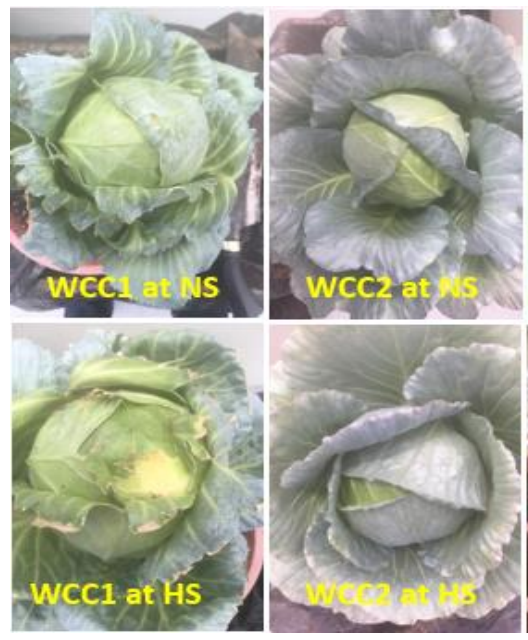

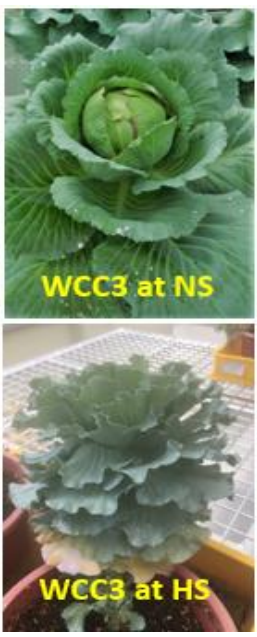

(a)

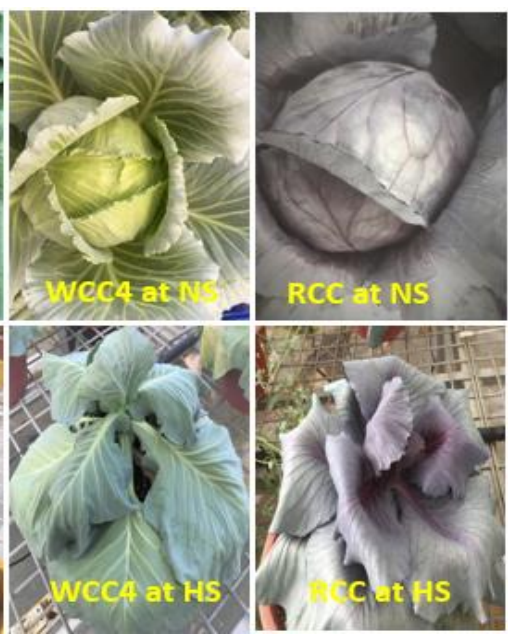

26rect at is

Figure 1. Cont. 


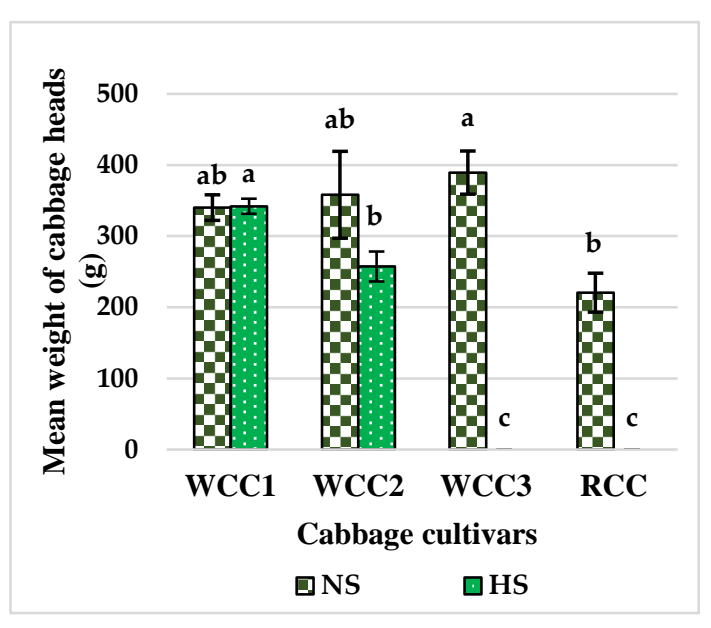

(b)

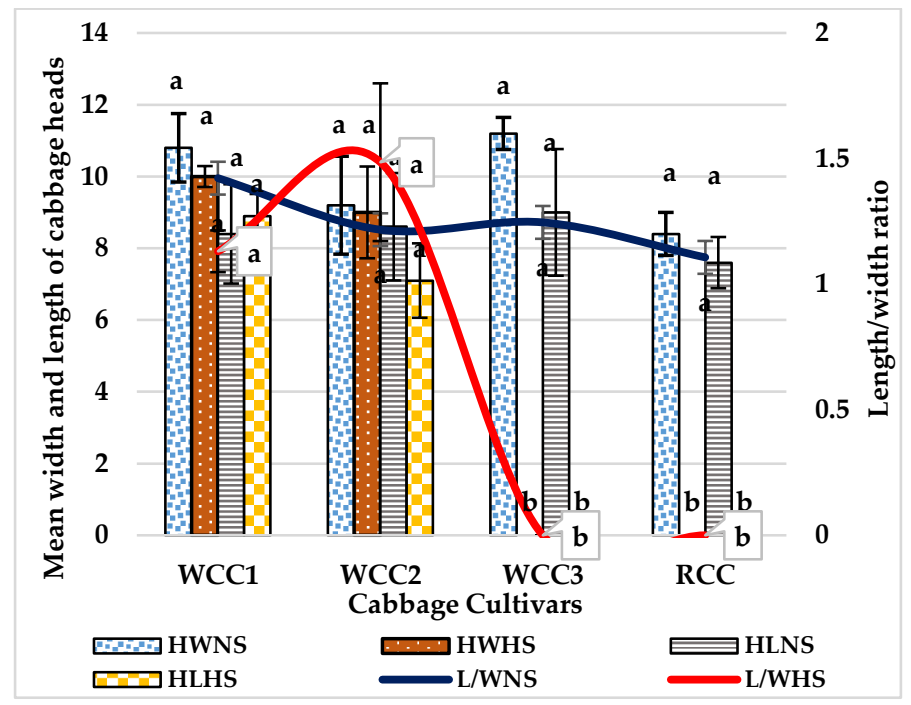

(c)

Figure 1. Effects of heat stress (HS) on morphological characteristics of different cabbage cultivars. Comparison of (a) HS phenotype of cabbage head formation, (b) mean head weight and (c) mean head width, length and their ratios. Bars denote the mean \pm SE $(n=5)$. Mean values within each cultivar with different letters are significantly different based on Tukey's HSD test at $p<0.05$.

\subsection{Effect of Heat Stress on Chlorophyll Content in Brassica oleracea Cultivars}

A large variation among cultivars was observed for the $\mathrm{CM} 1000^{\mathrm{TM}}$ chlorophyll index values (Figure 2a) under HS and NS conditions. The chlorophyll index values in the majority of HS-treated cabbage cultivars (except for WCC1) were affected by heat stress and were expectedly reduced as compared to the control plants. In particular, heat stress reduced the chlorophyll content of white cabbage cultivars WCC2 and WCC 3 and the red cabbage cultivar RCC as compared to control. Meanwhile, a higher reduction in chlorophyll content was observed in RCC, WCC 3 and WCC 2 by -1.2 -fold, -1.11 -fold and -1.11 -fold. In addition, an increment in chlorophyll content was observed in WCC1 by +0.9 -fold. It is thought that the chlorophyll content in WCC1 was increased under HS conditions because the leaves of WCC1 may respire faster leading to an increase in photosynthesis compared to control. Then, the chlorophyll accumulates in the leaves in higher amounts under stress than in the control. This enables the crop plants to complete their life cycle earlier under stress conditions through physiological adaptation.

The relative reduction of $\mathrm{CM} 1000^{\mathrm{TM}}$ chlorophyll content (\%CMCC) caused by HS was evaluated through the comparison of $\mathrm{CM} 1000^{\mathrm{TM}}$ values between NS and HS cultivars. Notably, the highest percentage of reduction in chlorophyll content under HS occurred in the RCC by $26.86 \%$, despite having a considerable value in the $\mathrm{CM} 1000^{\mathrm{TM}}$ chlorophyll index. Additionally, heat stress significantly induced reduction in chlorophyll, and the content of this molecule reduces in WCC2, WCC 3 and WCC4 by $16.35 \%, 11.16 \%$ and $7.8 \%$, respectively. Whereas, WCC1 did not show any relative reduction in the content of chlorophyll under HS (Figure 2b).

\subsection{Effect of Heat Stress on Stomatal Conductance in Brassica oleracea Cultivars}

Our results showed that the rate of stomatal conductance for cabbage cultivars in NS ranged from $214 \mu \mathrm{mol} \mathrm{m}^{-2} \mathrm{~s}^{-1}$ for WCC3 as the lowest rate to $324.4 \mu \mathrm{mol} \mathrm{m}{ }^{-2} \mathrm{~s}^{-1}$ for WCC1 as the highest rate. Some of the white cabbage cultivars including WCC1, WCC2 and WCC 3 when subjected to HS remarkably showed a slight increase in stomatal conductance rates compared to the control condition, apart from WCC4 and RCC, which showed a considerable reduction in stomatal conductance. The increment in stomatal conductance was higher under HS for WCC1 $\left(424.23 \mu \mathrm{mol} \mathrm{m}^{-2} \mathrm{~s}^{-1}\right)$ (Figure 3). There 
is a direct correlation between heat tolerance and the ability of plant to sustain leaf gas exchange and $\mathrm{CO}_{2}$ assimilation rates under $\mathrm{HS}$ [4]. The magnitude of change of stomatal aperture size (opening or closing) in response to high temperatures and boosted $\mathrm{CO}_{2}$, along with the effects on associated physiological processes such as $E$ and $A$, differed between the cultivars. The interplay between temperature increment resulting in increasing stomatal conductance, and elevation of $\mathrm{CO}_{2}$, which leads to decrease stomatal conductance, differed between the cultivars, suggesting that it could contribute to the differences in behaviour among cultivars in the predicted future climate [22].

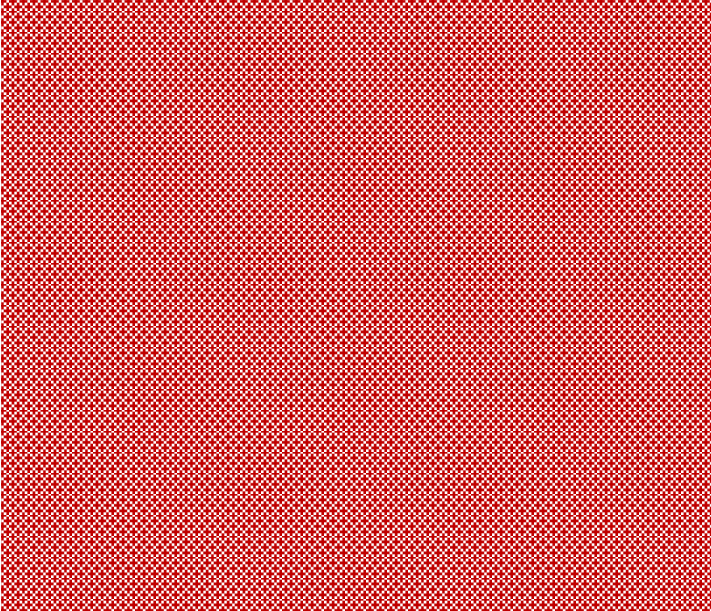

(a)

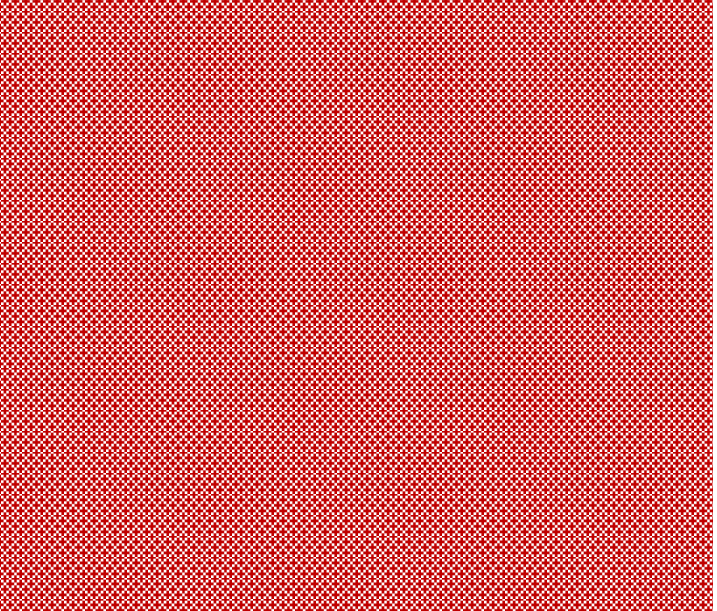

(b)

Figure 2. Mean phenotypic expression of chlorophyll content. (a) CM1000 ${ }^{\mathrm{TM}}$ chlorophyll content index values and (b) mean percentage of relative reduction in chlorophyll content in five cabbage cultivars under $\mathrm{HS}$ (at $42{ }^{\circ} \mathrm{C}$; for $5 \mathrm{~h}$ ) and NS ( $25{ }^{\circ} \mathrm{C}$ ) conditions. Bars denote the mean of at least 5 measurements \pm SE $(n=5)$. Mean values within each cultivar with different letters are significantly different based on Tukey's HSD test at $p<0.05$.

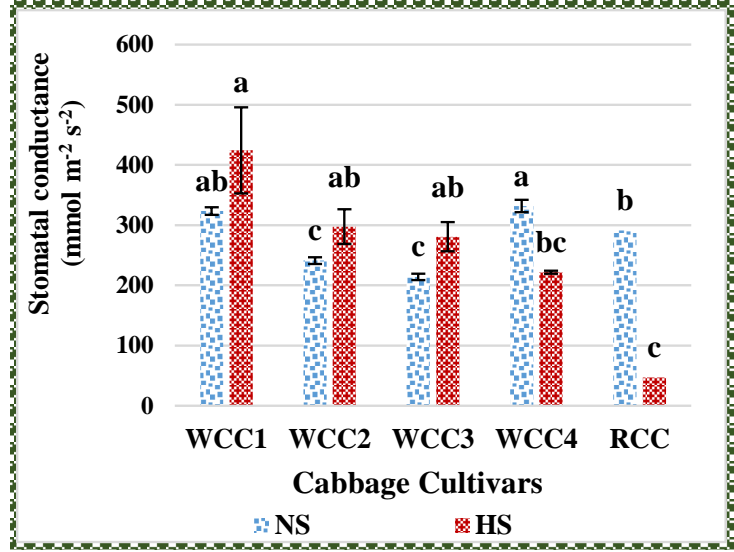

Figure 3. Mean phenotypic expression of stomatal conductance $\left(\mathrm{mmol} \mathrm{m}^{-2} \mathrm{~s}^{-1}\right)$ of five cabbage cultivars under HS (at $42{ }^{\circ} \mathrm{C}$; for $5 \mathrm{~h}$ ) and NS $\left(25^{\circ} \mathrm{C}\right)$ conditions. Bars denote the mean of at least 4 measurements \pm SE. Mean values within each cultivar with different letters are significantly different based on Tukey's HSD test at $p<0.05$.

\subsection{Effect of Heat Stress on Chlorophyll fluorescence in Brassica oleracea Cultivars}

Since the emitted chlorophyll fluorescence from plant leaves provides a valuable insight into the health of the photosynthetic systems within the leaf, chlorophyll fluorescence has been used as an indicator for HS tolerance. In our experiment, high temperature treatment also modified the chlorophyll fluorescence emission in stressed white and red cabbage cultivars. Thus, in all of these cabbage cultivars, initial fluorescence $(F o)$ values increased (Figure 4a). Meanwhile, the values of maximum chlorophyll fluorescence $(\mathrm{Fm})$ 
were also increased in the treated plants (Figure $4 \mathrm{~b}$ ) at the end of the heat stress in relation to the control treatment. Maximum photochemical efficiency of photosystem II (PSII) in dark-adapted leaves, expressed as Fv/Fm (Figure 4c), was reduced in all of the stressed cultivars of white and red cabbages at the end of the heat treatment. Particularly, more significant and higher reduction in $\mathrm{F} v / F m$ was observed in the heat-stressed cabbage cultivars WCC4, RCC and WCC 3, with values of $0.47,0.51$ and 0.65 compared to all of the NS cabbage cultivars with their $F v / F m$ above 0.8 . In addition, heat stress noticeably diminished the photosynthetic performance index $\left(P I_{A B S}\right)$ of all the white and red cabbage cultivars, WCC1, WCC2, WCC 3 , WCC4 and RCC by $58.7 \%, 43.7 \%, 77.1 \%, 90.1 \%$ and $91.5 \%$, respectively, compared to control (Figure $4 \mathrm{~d}$ ). The values of the $P I_{A B S}$ parameter derived from chlorophyll fluorescence records confirmed a much higher responsiveness of $P I_{A B S}$ compared to $\mathrm{Fv} / \mathrm{Fm}$. The values in HS treatment were significantly lower in both white and red cabbages in all cultivars. Moreover, the $P I_{A B S}$ values indicated a lower photosynthetic performance of HS-treated cultivars compared to NS.

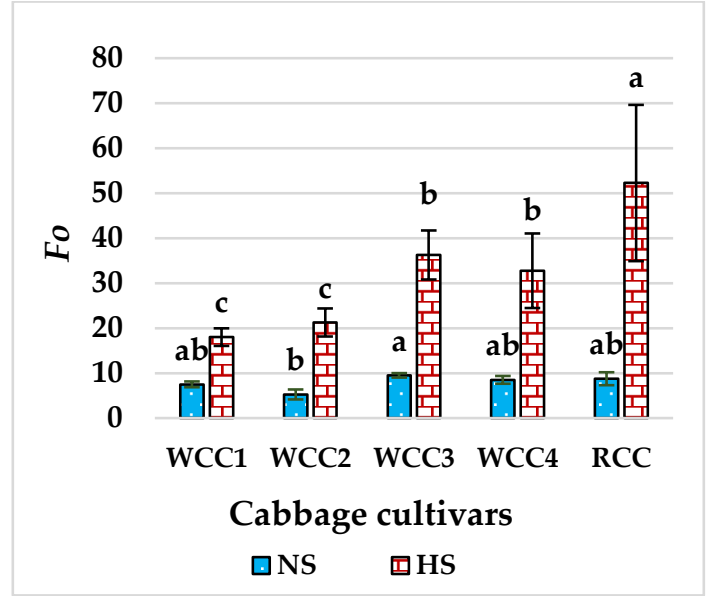

(a)

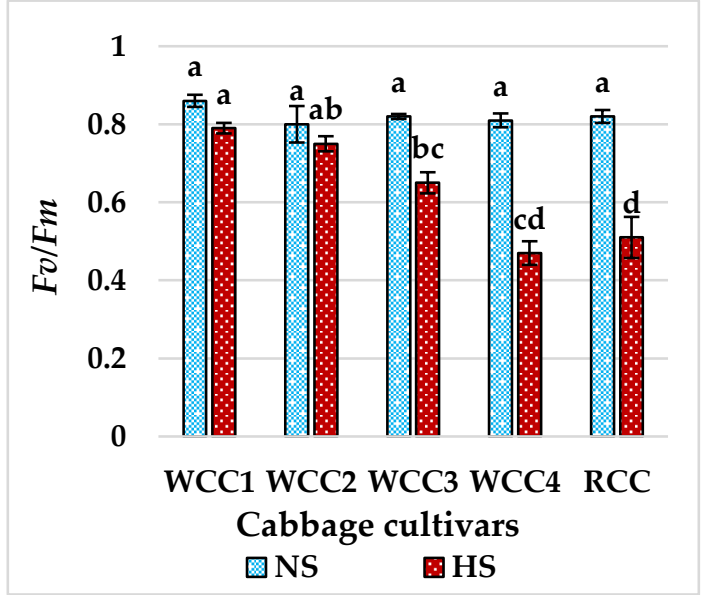

(c)

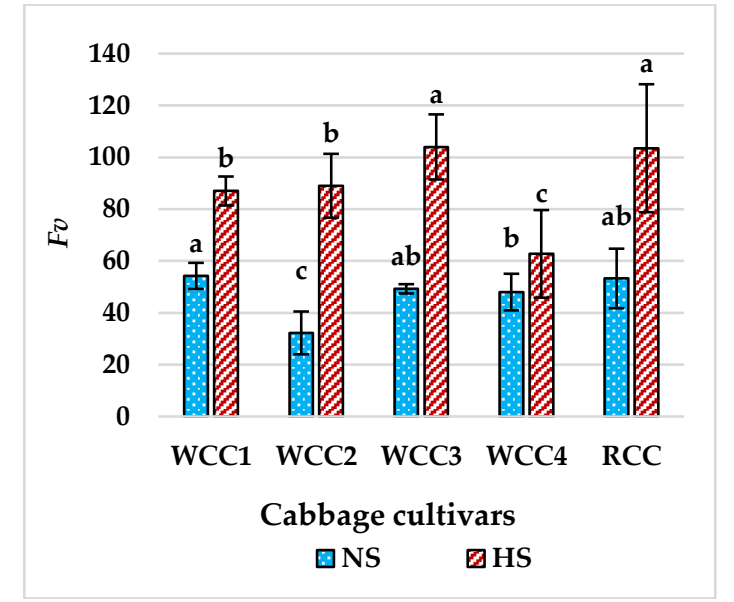

(b)

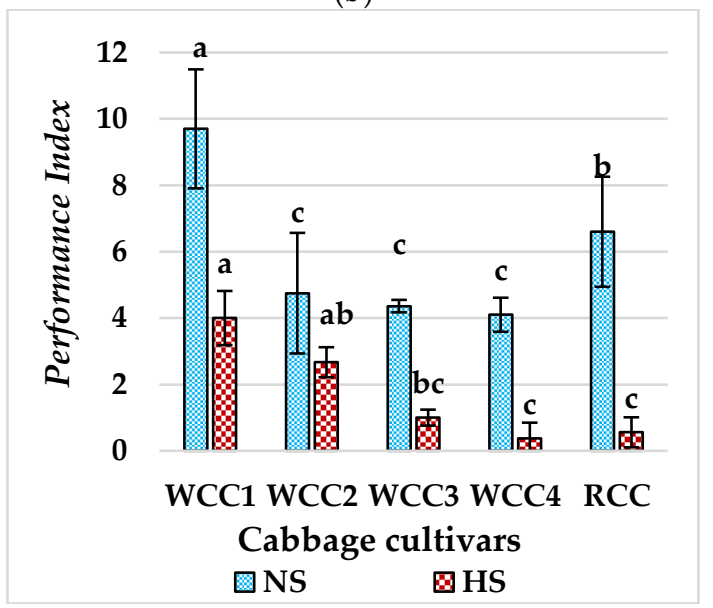

(d)

Figure 4. Mean phenotypic expression of chlorophyll fluorescence under HS. (a) Comparison of minimum fluorescence ( $F o$ ) in five cabbage cultivars, (b) comparison of variable fluorescence ( $F v)$ in five cabbage cultivars, (c) comparison of the $F v / F m$ ratios in five cabbage cultivars measured and (d) comparison of photosynthetic performance index $\left(P I_{A B S}\right)$ in five cabbage cultivars. All measurements were performed under HS (at $42{ }^{\circ} \mathrm{C}$; for $5 \mathrm{~h}$ ) and NS $\left(25^{\circ} \mathrm{C}\right)$ conditions. Bars denote the mean of at least 5 measurements \pm SE. Mean values within each cultivar with different letters are significantly different based on Tukey's HSD test at $p<0.05$. 


\subsection{Effect of Heat Stress on Cell Membrane Thermostability (CMT) and Relative Thylakoid Damage in Brassica oleracea Cultivars}

CMT values show significant differences between white and red cabbage cultivars (Figure 5a) at the end of the heat treatment, even though CMT values ranged from $43.9 \%$ for WCC 3 to $88.6 \%$ for WCC1. Meanwhile, there were also significant relationships between relative injury (RI) as an index of the CMT of the heat-stressed white cabbage cultivar WCC 3 and the red cabbage cultivar RCC by $56.1 \%$ and $40.7 \%$, respectively. The CMT test is based on the fact that the injury inflicted on leaf tissues under high temperatures weakens the cell membrane, which leads to a leakage of electrolytes out of the cell [23]. Moreover, consistent with our chlorophyll content measurement results (Figure 2a,b), the reduction in chlorophyll pigment might be the effect of lipid peroxidation of thylakoid membranes and chloroplasts. In order to evaluate the impact of HS on thylakoid membrane damage (TMD), the $F_{V} / F_{M}$ values between NS and HS cultivars were compared accordingly. Different cultivars revealed clear differences for relative damage to cell membrane and thylakoid caused at high temperatures (Figure 5b). In particular, the lowest percentage of thylakoid membrane damage due to the high temperatures was recorded for WCC1 at $8 \%$ and WCC2 at $8.5 \%$ among all heat-stressed cabbage cultivars. This indicates that these cultivars can remain physiologically active for a longer period following experiencing HS. Whereas, heat-shock RCC and WCC4 more significantly demonstrated higher thylakoid membrane damage under high-temperature stress, by $41.7 \%$ and $37.7 \%$, respectively.

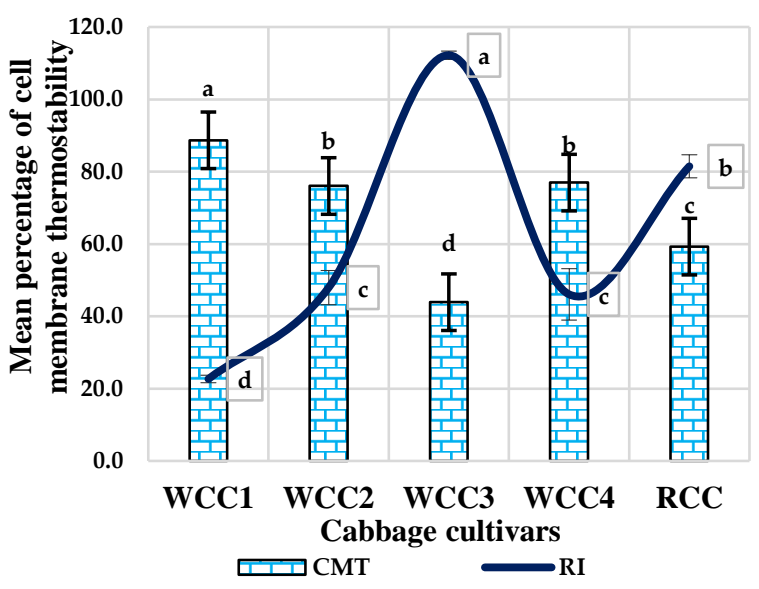

(a)
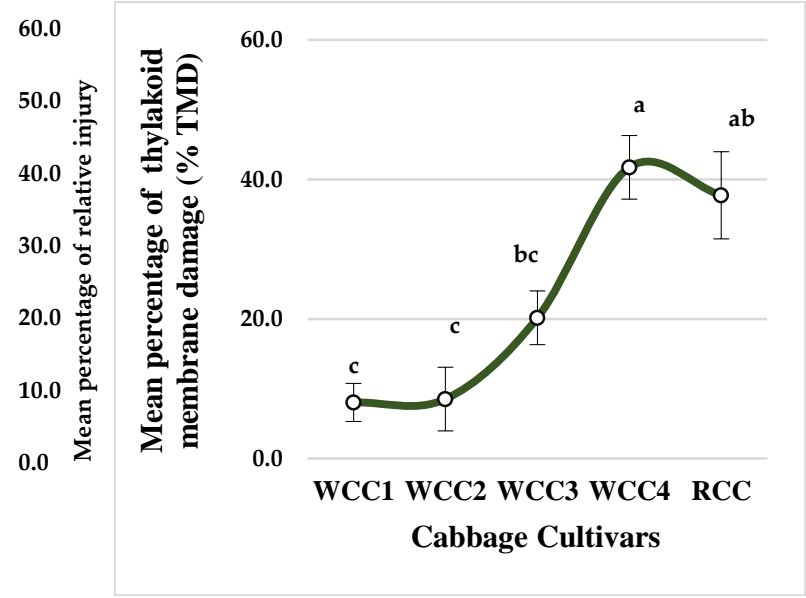

(b)

Figure 5. (a) Cell membrane thermostability (CMT) index and relative injury as determined by CMT and (b) mean percentage of damage to thylakoid membrane of in five cabbage cultivars measured under HS (at $42{ }^{\circ} \mathrm{C}$; for $5 \mathrm{~h}$ ) and NS $\left(25^{\circ} \mathrm{C}\right)$ conditions. Bars denote the mean of at least 5 measurements \pm SE $(n=5)$. Mean values within each cultivar with different letters are significantly different based on Tukey's HSD test at $p<0.05$.

To summarize, Table 1 is a summary of all the physiological and morphological parameters used to evaluate the effects of high temperatures comprehensively, using indicator values as reference for the selection of heat-tolerant cabbages that have been generated by employing state-of-the-art, precision and useful tools. 
Table 1. A summary of physiological and morphological parameters evaluated in this study can be used as indicators for the selection of heat tolerance in cabbage.

\begin{tabular}{cccc}
\hline Paramaters & \multicolumn{3}{c}{ Heat Tolerance Indicators } \\
\hline & Heat Tolerance & Moderate Tolerance & Sensitive \\
\hline Reduction of chlorophyll content & $\mathrm{X}<10$ & $\mathrm{X}=10.0-20.0$ & $\mathrm{X}>20.0$ \\
Stomatal conductance & $\mathrm{X}>300$ & $\mathrm{X}=200-300$ & $\mathrm{X}<300$ \\
Fv/Fm & $\mathrm{X}>0.75$ & $\mathrm{X}=0.6-0.75$ & $\mathrm{X}<0.6$ \\
Cell membrane thermostability & $\mathrm{X}>60 \%$ & $\mathrm{X}=30-60 \%$ & $\mathrm{X}<30 \%$ \\
Head formation & Yes & Yes & No \\
\hline
\end{tabular}

2.6. Expression Pattern of BoHSP70 and BoSCL13 as Specific Marker Genes for the Heat Tolerance Trait in Cabbage

Three biological replicates consisting of one HSC white cabbage (WCC3) and one HTC white cabbage (WCC1) together with one HSC red cabbage (RCC) from the same treatments for the morphophysiological studies mentioned above were used in this study. For the gene expression analysis, the samples were harvested after $\mathrm{HS}$ at $42^{\circ} \mathrm{C}$ for 3 and $5 \mathrm{~h}$, and for control samples (NS), the seedlings were continually grown at $25^{\circ} \mathrm{C}$. We performed RT-qPCR analyses to evaluate the transcript levels of BoHSP70 under HS conditions. The expression level of BoHSP70 in RCC and WCC1 exposed to HS at $42{ }^{\circ} \mathrm{C}$ for $3 \mathrm{~h}$ showed a slight increase by 1.36-fold and 1.13-fold, respectively, whereas WCC 3 showed a slight decrease by 0.45 -fold. Continuous incubation of cabbage plants under HS at $42{ }^{\circ} \mathrm{C}$ for $5 \mathrm{~h}$ resulted in a dramatic increase in the expression of BoHSP70 in all cultivars. RCC expressed the highest increase in transcript level of BoHSP70 by 70.7-fold followed by a moderate upregulation in WCC1 (23.5-fold) and WCC3 (15.7-fold) (Figure 6a). The results of this investigation showed that the expression of BoHSP70 is constitutive and highly enhanced by HS in HSC and HTC, as in AtHSP70 [2]. The previous Genechip microarray analysis revealed that BoSCL13 could be a marker to distinguish HTC lines because an increased expression of this gene is thought to be pertinent to heat tolerance and/or good cabbage-head formation at high temperatures [2]. Thus, we carried out RT-qPCR analyses to evaluate the transcript levels of BoSCL13 under HS conditions to determine the typical heat-induced expression of BoSCL13 (Figure 6b). Our results revealed that the expression pattern of BoSCL13 was only induced in WCC1 compared to RCC and WCC 3 cultivars at $42{ }^{\circ} \mathrm{C}$ for $3 \mathrm{~h}$. Whereas, the BoSCL13 expression pattern increased in the RCC and WCC1 cultivars but not in WCC 3 under HS-treated plants at $42{ }^{\circ} \mathrm{C}$ for $5 \mathrm{~h}$. The results of the BoSCL13 expression pattern found in this investigation are similar to the findings reported by Park et al. (2013) [2].

\subsection{Analysis of Fold Change in Expression of DPB3-1 and DRIP1 in Heat-Tolerant and Heat-Sensitive Cabbage Cultivars}

We evaluated the transcript levels of BoDPB3-1 and BoDRIP1 under HS $42^{\circ} \mathrm{C}$ for 3 and $5 \mathrm{~h}$ (Figure 7). BoDPB3-1 showed significantly higher expression at $42{ }^{\circ} \mathrm{C}$ for $5 \mathrm{~h}$ of $\mathrm{HS}$ in WCC 1 by 4.3 -fold and WCC 3 by 3.5 -fold compared to NS, whereas the expression pattern of BoDPB3-1 in HS-treated RCC was relatively downregulated under HS conditions at $42^{\circ} \mathrm{C}$ for both $3 \mathrm{~h}$ and $5 \mathrm{~h}$ by 0.87 -fold and 0.35 -fold, respectively (Figure $7 \mathrm{a}$ ). Further, the expression level of BoDRIP1 was only induced in WCC1 by 1.28 -fold under HS conditions at $42{ }^{\circ} \mathrm{C}$ for $5 \mathrm{~h}$, whereas the transcript level of BoDRIP in WCC 3 was decreased during HS at $42{ }^{\circ} \mathrm{C}$ for $5 \mathrm{~h}$. The expression pattern of BoDRIP was relatively downregulated at $42{ }^{\circ} \mathrm{C}$ for $3 \mathrm{~h}$ in all cabbage cultivars (Figure $7 \mathrm{~b}$ ). 


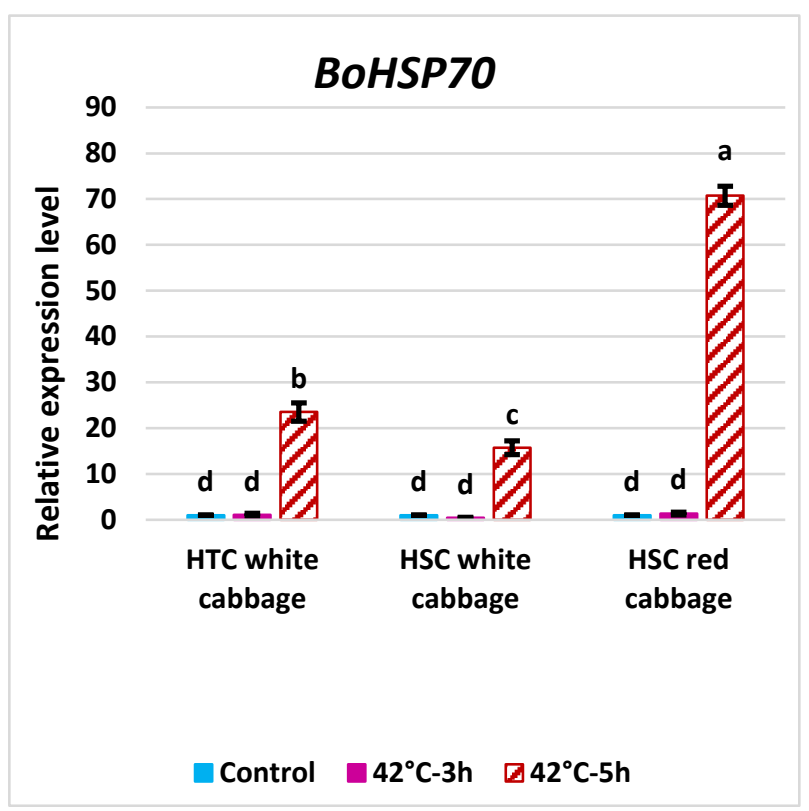

(a)

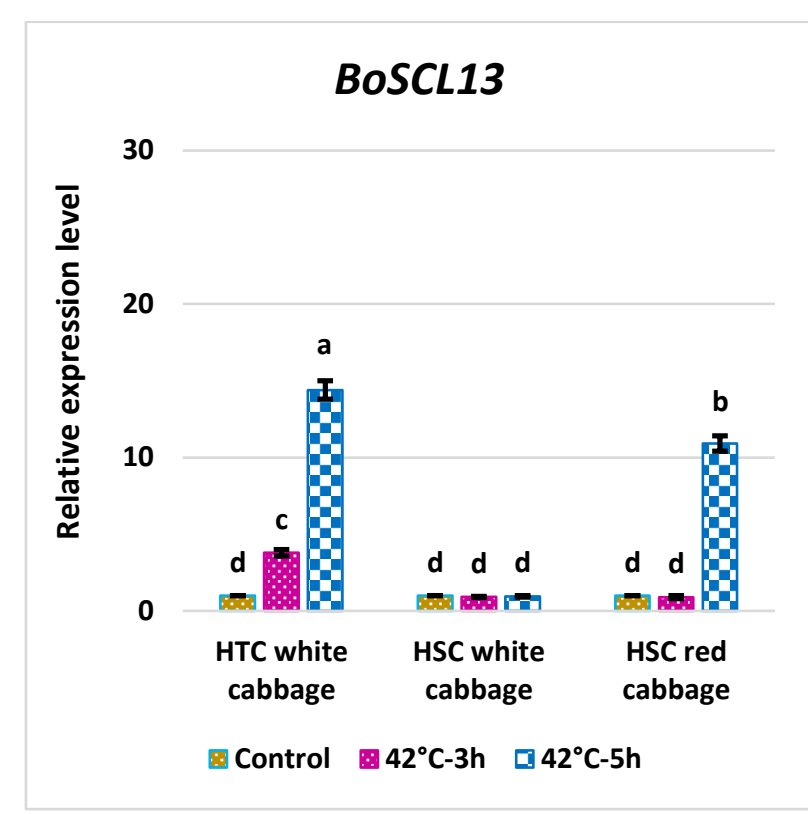

(b)

Figure 6. Expression pattern of (a) BoHSP70 and (b) BoSCL13 as specific marker genes for the heat tolerance trait in cabbage cultivars. Four-week-old plants were HS treated at $42{ }^{\circ} \mathrm{C}$ for 0,3 and $5 \mathrm{~h}$. The expression levels at $0 \mathrm{~h}$ were defined as 1.0 and non-stress condition (control). Bars denote the mean \pm SE $(n=3)$. Mean values within each cultivar with different letters are significantly different based on Tukey's HSD test at $p<0.05$.

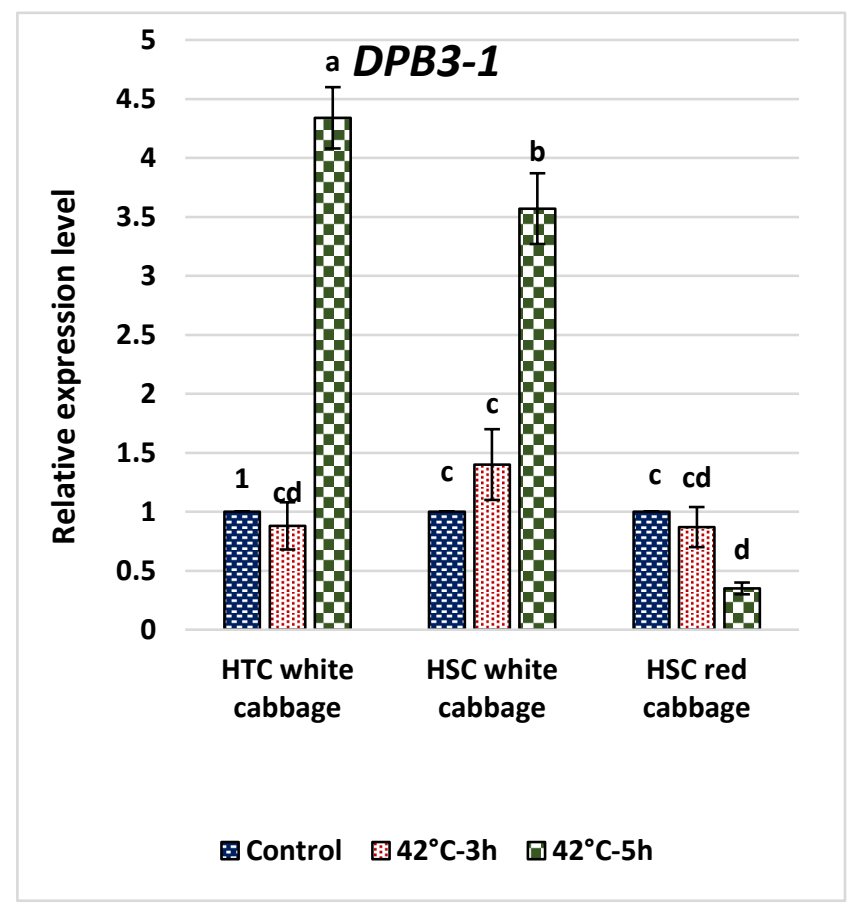

(a)

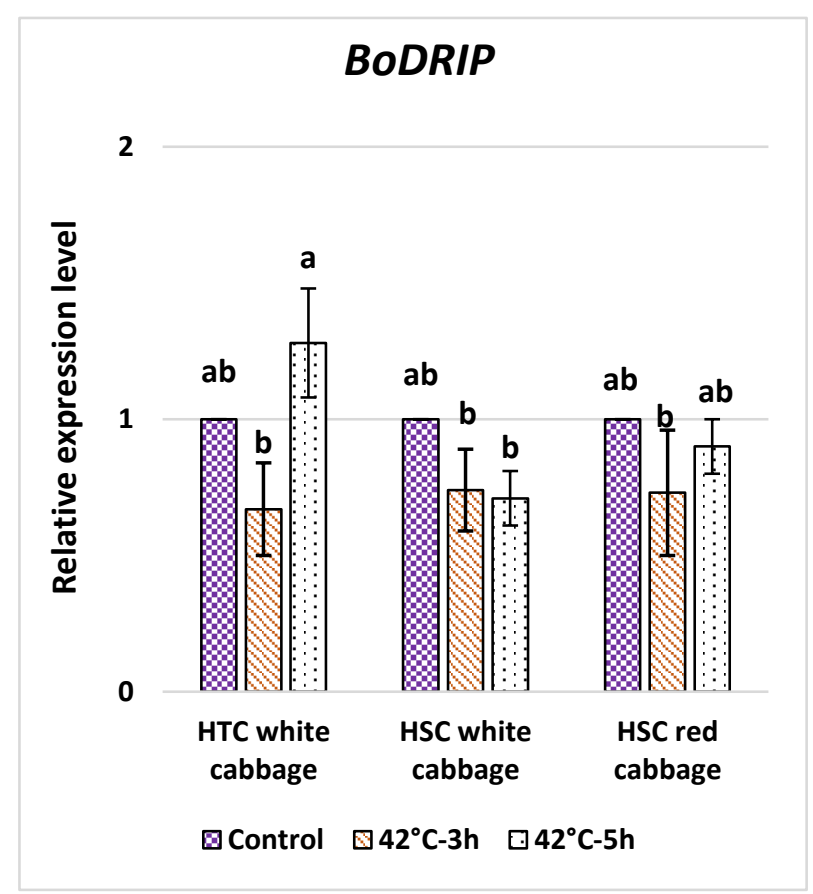

(b)

Figure 7. Expression pattern of key heat-stress response transcriptional regulators, (a) BoDPB3-1 and (b) BoDRIP, in red cabbage compared to heat-tolerant and -sensitive cabbage cultivars. Four-week-old plants were HS treated at $42{ }^{\circ} \mathrm{C}$ for 0 , 3 and $6 \mathrm{~h}$. The expression levels at $0 \mathrm{~h}$ were defined as 1.0 and non-stress condition (control). Bars denote the mean $\pm \mathrm{SE}$ $(n=3)$. Mean values within each cultivar with different letters are significantly different based on Tukey's HSD test at $p<0.05$. 


\section{Discussion}

To mitigate the effects of HS, it is important to screen some indicators (Table 1) to determine cultivars that can withstand environmental challenges. In this study, we evaluated the physiological data, morphological characteristics and the expression levels of key genes in different heat-response pathways influenced by the thermostability of different B. oleracea cultivars. In plants, photosynthesis is one of the physiological processes that is greatly affected by heat [24]. The impact of HS is mostly on the photosynthetic capacity of plants, especially C3 plants such as the Brassica species compared to C4 plants because of the decline in ribulose-1, 5-bisphosphate carboxylase/oxygenase (rubisco) activity and $\mathrm{CO}_{2}$-specificity of rubisco. The reduction in rubisco activity under $\mathrm{HS}$ may decrease the capacity of photosystem I to function as an electron receiver from photosystem II (PSII), possibly intensifying the negative effect of HS on PSII $[25,26]$.

\subsection{High Temperatures Decrease the Content of Chlorophyll in Brassica oleracea Cultivars}

Our results clearly demonstrate that leaf chlorophyll content as measured by $\mathrm{CM} 1000^{\mathrm{TM}}$ index values varied between cultivars, but it is uncertain whether cultivars with higher $\mathrm{CM}_{1000^{\mathrm{TM}}}$ value are heat tolerant. Chlorophyll content is one of the plant physiological characteristics influenced by HS [27]. Our results showed that heat stress reduced the chlorophyll content of most of the white cabbage cultivars and red cabbage cultivars. It is well understood that under HS, the activity of chlorophyll-degrading peroxidase and chlorophyllase rises, and the content of chlorophyll is extremely diminished [28].

\subsection{High Temperatures Damage the Thylakoid Membrane of the Ultrastructure of Chloroplasts in Brassica oleracea Cultivars}

The high sensitivity of photosynthesis to high temperatures and the inconsistency of cellular energy caused by heat damage are irrefutable, which is largely reflected in the discrete modification to the redox state relevant to the injury of thylakoid membranes [28]. The stroma of chloroplasts where carbon metabolism occurs, and the thylakoid lamellae where photochemical reactions take place are considered the primary sites of injury at high temperatures $[29,30]$. In the present study, candidate cultivars from white and red cabbage species showed clear variations in relative damage to the cell membrane and thylakoid resulting from HS. For example, in our investigation of white cabbage, there are cultivars with the least thylakoid membrane damage due to injury at high temperatures. Most probably, these cultivars can withstand major alterations in chloroplasts under HS, such as an altered structural organization of thylakoids, loss of grana stacking and swelling of grana [31,32]. Heat-tolerant Brassica cultivars (WCC1 and WCC2) in this study showed much better cell membrane thermostability compared to heat-sensitive Brassica cultivars of the white and red cabbage cultivars (WCC 3 and RCC) under HS conditions. The PSII activity was also considerably abated or unexpectedly stopped under high temperatures for both HTC and HSC, consistent with the report by Morales et al. (2003) and Hu et al., (2020) $[28,33]$.

\subsection{High Temperatures Damage the PSII and REDUCE Fv/Fm in Brassica oleracea Cultivars}

Chlorophyll, the key photosynthetic pigment in the chloroplasts' thylakoid membrane, can intake light energy and stimulate electron transfer during the initial and crucial processes of photosynthesis [34]. However, HS decreases the amount of photosynthetic pigments [30]. Fv/Fm is generally used to analyse heat-induced damage to PSII [35], and HS decreases $\mathrm{Fv} / \mathrm{Fm}$ in a variety of plant species [36]. For many plant species, the approximate optimal $\mathrm{Fv} / \mathrm{Fm}$ value ranges from 0.79 to 0.84 , with lowered values indicating plant stress [37]. In this study, Fv/Fm was reduced in all of the stressed cultivars of white and red cabbages under HS. In particular, less reduction in Fv/Fm was observed in HTC of WCC1 and WCC2 (0.79 and 0.75) compared to the other NS cabbage cultivars with their Fv/Fm above 0.8 . 


\subsection{High Temperature and Its Impact on Stomatal Conductance, Photorespiration and Photosynthesis in Brassica oleracea Cultivars}

Stomatal conductance directly alters the relation of plant water and photosynthesis [22]. Heat considerably influences the status of leaf water, intercellular $\mathrm{CO}_{2}$ concentration and leaf stomatal conductance. Consistently, in this study the HSCs of Brassica species showed a reduction in stomatal conductance as demonstrated by WCC4 and RCC compared to NS plants. Closure of stomata under high temperatures also leads to impaired photosynthesis, affecting the intercellular $\mathrm{CO}_{2}$ [31]. Furthermore, with rising temperatures, the rubisco affinity for $\mathrm{CO}_{2}$ declines, which boosts oxygenase activities. This results in an increase in photorespiration and reduction in photosynthesis efficiency, eventually reducing crop yields [28]. The decline in chlorophyll pigment is also the result of the lipid peroxidation of chloroplast and thylakoid membranes as shown in cabbage due to HS. Our findings clearly demonstrated that PSII photochemistry (proportion of $F_{v} / F_{m}$ ) and leaf stomatal conductance also decrease under HS. The present study shows that HS significantly decreased chlorophyll content $(20.5 \%), F_{v} / F_{m}$ ratio $(27 \%), g s(16 \%)$ and CMT (44\%) in heat-sensitive Brassica cultivars. According to [38], CMT above $60 \%$ is an indicator of heat tolerance, $30 \%$ to $60 \%$ moderate tolerance and less than $30 \%$ indicates sensitivity to HS. The mean value obtained for CMT in this study agrees with the work of [23], where CMT was measured in five cabbage cultivars of white and red cabbages. In particular, electrical conductivity has been employed as an indicator of perturbation of membrane permeability to identify heat-tolerant genotypes in B. oleracea species [23] and for screening for heat tolerance in different crops $[39,40]$.

\subsection{GeneMANIA Helps to Predict the Function of Genes and Gene Sets}

The application of a bioinformatics tool, GeneMania, enabled a co-expression network to be produced showing how candidate genes of interest in this study interact with each other. GeneMANIA covers 10,244,303 edges between 24,815 Arabidopsis genes [41] and also contains a richer network to find associations between genes. GeneMANIA uses a more advanced strategy, taking into account global connectivity between genes and also further exploiting indirect connections in the network [42]. Our GeneMANIA gene-gene interaction network shows that there is about $66.87 \%$ of physical interaction among the target genes in this study, including BoHSP70, BoSCL13, BoDPB3-1 and BoDRIP1. BoDRIP1 acts as an E3 ubiquitin-protein ligase performing as a negative regulator of the response to water stress. It mediates ubiquitination and subsequent proteasomal degradation of the drought-induced transcriptional activator, DREB2A. Our GeneMANIA gene-gene interaction network showed that DREB2A is an intermediator between the BoHSP70 group and the BoDRIP1 group, with about $14 \%$ of predicted interactions among them. RING1B performs as a putative E3 ubiquitin-protein ligase that mediates mono-ubiquitination of "Lys-119" of histone H2A (H2AK119ub), thereby playing a central role in the histone code and gene regulation. RING1B here is an intermediator in the interaction between the BoDRIP1 group of genes and the BoDPB3-1 (NF-YC10) group of genes (Figure S1).

\subsection{High Temperature and the Phenotypic Differences between HTCs and HSCs}

In this study, HTCs showed the most noticeable cabbage head formation compared to HSCs. The HTC can be differentiated based on their better ability in forming heads at high temperatures [2]. Several reports have shown that cabbage head formation is significantly influence by genotype-environment interaction [11]. In our study, the HTCs began head formation in the vegetative stage, unlike the HSCs. Relevant to the morphological characteristics, the transcript levels of BoSCL13 were induced in heat tolerant-cabbage lines under HS, suggesting that BoSCL13 may be involved in heat tolerance and/or better cabbage head formation under HS [2]. Consistent with this report, our results demonstrated that the expression pattern of BoSCL13 was induced in HTC white cabbage by 3.8-fold compared to HSC red cabbage and HSC white cabbage at $42{ }^{\circ} \mathrm{C}$ for $3 \mathrm{~h}$. Our findings support the use of BoSCL13 as a marker to distinguish HTCs at an early stage following heat treatment. 
Furthermore, BoSCL13, which showed further enhanced expression in HTC white cabbage by 14.4-fold compared to NS but was not expressed in HSC white cabbage at $5 \mathrm{~h}$ under HS, can be used to differentiate HTC from HSC in white cabbage cultivars only, as strongly induced expression of this gene was observed in HSC red cabbage (10.91) at $5 \mathrm{~h}$.

3.7. Analysis of Fold Change in the Expression of Key Genes in the HS Response Network and Evaluating Potential Molecular Indicators to Differentiate HTC from HSC in Brassica oleracea

Among all the gene-gene interactions, BoHSP70 appeared to be an important component of the mediator complex. BoHSP70 acts in cooperation with other chaperones (HSP70s, HSP70-15, HSP70-5, HSP17-7 and DNAJ heat-shock family protein) which are key components that facilitate the folding of de novo synthesized proteins, assist the translocation of precursor proteins into organelles and are responsible for the degradation of damaged proteins under stress conditions with about $12.7 \%$ co-expression interaction (Figure S1). Strongly induced expression of BoHSP70 observed for all three cultivars under HS compared to NS plants at 5h suggested that BoHSP70 can be used as expression biomarker to monitor HS in both white and red cabbage cultivarsm supporting the findings by Park et al., (2013). The enhanced expression of BoSCL13 in HSC red cabbage could be due to the interaction of co-expressing SCL13 with HSPs as shown in the gene-gene interaction network (Figure S1) and confirmed by our gene expression analysis of BoHSP70 and BoSCL13 in HSC red cabbage. The pigments in the red cabbage belong to a group of compounds called anthocyanins, which are part of a larger group of structures called flavonoids [43]. The role of HSPs in protecting enzymes from denaturation and cellular degeneration is possibly retained with prolonged HS in RCC, most likely due to the high accumulation of pigment and flavonoids [44].

\subsection{The Expression of BoDRIP as a Negative Regulator Domain of DREB2A Contrary to} BoDPB3-1 as a Positive Interactor of DREB2A

Two mechanisms may influence the DREB2A HS response pathway which target the selectivity $[18,45]$ and regulation of protein stability [46,47]. In order to investigate the first mechanism, we studied the expression of BoDPB3-1, a DREB2A interactor for enhanced selectivity of HS response genes by DREB2A. BoDRIP, which is involved in the $26 \mathrm{~S}$ proteasome degradation pathway of proteins, was used to study the second mechanism. DPB3-1 (NFYC10) and NF-YB3 are heat stress-inducible genes, and NF-YB3 is transported to the nuclei under HS. Together, DPB3-1, NF-YB3 and NF-YA2 form a trimer which enhances the transcriptional activity of DREB2A. Previous reports elucidated that in the presence of DPB3-1, the stabilized DREB2A induces the expression of HS-responsive genes through binding to a dehydration-responsive element found in their promoters [14]. Our results confirmed that expression of the BoDPB3-1 gene was induced by HS in both HTC and HSC white cabbages but was supressed in HSC red cabbage. The expression level of BoDPB3-1 in HSC red cabbage exposed to HS at $42^{\circ} \mathrm{C}$ for $3 \mathrm{~h}$ and $5 \mathrm{~h}$ showed a slight repression by 0.87 -fold and 0.35 -fold, respectively. The HSC red cabbage plants revealed considerably higher sensitivity to heat than the HTC and HSC white cabbage plants from our physiological measurements and morphological characteristics. The increased sensitivity to heat stress in HSC red cabbage shows an important role of DPB3-1 in the HS response. Since expression of DPB3-1 was not induced in prolonged HS exposure, the trimer involving DPB3-1 cannot form in HSC red cabbage for the activation of DREB2A transcriptional activity. In Arabidopsis, the reduced expression of DPB3-1 suppressed the expression of heat stress-inducible genes [15]. To the best of our knowledge, this is the first report of DPB3-1 on gene expression in B. oleracea cultivars for screening their HS tolerance.

\subsection{Opportunities for Crop Improvement for Heat Stress Tolerance}

Understanding the expression of HS-responsive genes and the interactions between them may help in the genetic improvement of vegetable crops. HTC will help to meet growing demands for sustainable and safe food production through molecular breeding and genetic engineering. The advent of CRISPR technology and the Cas9-associated protein 
and its catalytically dead version provide an influential genetic manipulation tool [48] to combat the effects of climate change which can drive forward crop improvement research in response to environmental stresses. This study has contributed to the validation of potential targets based on morpho-physiological measurements, gene expression profiles and the gene network interaction analysis under HS for greater precision in genetic manipulation.

\section{Materials and Methods}

\subsection{Plant Materials and Growth Conditions}

Seeds of two varieties of Brassica oleracea including var. capitate $\mathrm{f}$. alba and var. capitata $\mathrm{f}$. rubra were selected to conduct this study. Four commercial hybrid cultivars of white cabbage (Brassica oleracea var. capitate f. alba), named KAGAYAKI (WCC1), U. S Hybrid Cabbage (WCC2), PS Petoseed Hybrid Cabbage (WCC3) and Delta Green (WCC4), were used. Additionally, in order to see the variances better in this study, another commercial hybrid cultivar of red cabbage (Brassica oleracea var. capitate f. rubra), named Red Globe (called in this study RCC), was also selected (Table A2). All the hybrid seeds were obtained from the local market at Serdang, Selangor, Malaysia. Germination of soil-grown cabbage seeds was carried out in seedling trays containing sterilized and pasteurized peat moss. Germinated seeds were grown for four weeks, and the soil was kept evenly moist. Cabbage plants were fertilized when the plants were established with a high nitrogen fertilizer such as 10-5-5, $\mathrm{N}-\mathrm{P}-\mathrm{K}$, in polybags with $6 \mathrm{~kg}$ of potting mixture composted with sterilized and pasteurized 2/4-part peat moss, 1/4-part large vermiculite, 1/4-part perlite and irrigated through drip irrigation. The obtained plants were left to grow in a growth chamber at $24{ }^{\circ} \mathrm{C}$ for $16 \mathrm{~h}$ day and $8 \mathrm{~h}$ night cycles with $150 \mu \mathrm{E} \mathrm{m}^{-2} \mathrm{~s}^{-1}$ light. To examine phenotypic differences between HTCs and HSCs under HS, some cabbage cultivars were left to form cabbage heads at a higher temperature.

\subsection{Heat Treatments}

Four-week-old, young soil-grown cabbages were subjected to HS at $42{ }^{\circ} \mathrm{C}$ for $3 \mathrm{~h}$ and $5 \mathrm{~h}$ (HS) in an incubator or continuously grown in a growth chamber at $25 \pm 2{ }^{\circ} \mathrm{C}$ (NS) to form cabbage heads.

\subsection{Chlorophyll Measurements}

The chlorophyll content of each plant was measured indirectly by using a hand-held FieldScout CM $1000{ }^{\text {TM }}$ Chlorophyll Meter, Aurora, Illinois, USA. The CM1000 chlorophyll meter perceives light at wavelengths of $700 \mathrm{~nm}$ and $840 \mathrm{~nm}$ to assess the amount of chlorophyll in leaves. At each wavelength, the reflected light is estimated. The chlorophyll index values were measured on different varieties of $B$. oleracea, including white cabbage and red cabbage, when the plants were exposed to HS (at $42{ }^{\circ} \mathrm{C}, 5 \mathrm{~h}$ ) compared to NS (control at $25 \pm 2{ }^{\circ} \mathrm{C}$ ) conditions. The fourth opened leaf of each plant of five biological replications of cabbages per cultivar was used to measure the chlorophyll index values. Measurements of chlorophyll were carried out on the adaxial side of cabbage leaf for each plant. Averages of three readings were taken per leaf measurements. The mean value of all assessments was based on five replications obtained through statistical analysis according to Thomason et al. (2018). The relative reduction of CM 1000 chlorophyll content (CMCC) caused by HS was assessed through comparison of the $\mathrm{CM} 1000^{\mathrm{TM}}$ values between plants under control conditions and heat treatments. The relative chlorophyll content reduction was valued as

$$
\% \mathrm{CMCC}=[(\mathrm{CM} 1000 \text { control }-\mathrm{CM} 1000 \text { heat }) / \mathrm{CM} 1000 \text { control }] \times 100 .
$$

\subsection{Stomatal Conductance Measurements}

A leaf porometer (model SC-1, Decagon Devices, Inc., Pullman, WA, USA) was used to measure stomatal conductance $\left(\mathrm{mmol} \mathrm{m}^{-2} \mathrm{~s}^{-1}\right)$ on the abaxial side of the third fully expanded leaves of five biological replications of cabbages per cultivar at $\pm 10 \%$ 
accuracy $(n=4)$. Measurements of stomatal conductance were taken early in the morning (8-10 a.m.) for the control cabbage plants and $24 \mathrm{~h}$ after heat stress for the heat-treated plants. Instrument calibration was performed before each set of measurements based on the manufacturers' guidelines.

\subsection{Chlorophyll Fluorescence (CF) Test}

CF measurements were performed using a Handy-PEA chlorophyll fluorimeter device (Plant Efficiency Analyser, Hansatech instruments Ltd., Norfolk, UK). The photosynthetic efficiency was determined based on the value obtained for Fv/Fm, whence $F v=F m-F o$, as variable fluorescence in the dark-adapted state. Here, Fo is the minimal fluorescence state and is explained as the point where all antenna sites are not closed. The antenna complex is a light-harvesting membrane-associated aggregate of proteins and photosensitive pigments such as chlorophyll and carotenoids. They are situated inside the chloroplasts of photosynthetic organisms, capture the energy from light and transfer it to the reaction centre where chemical reactions take place [49]. Fm (Maximal fluorescence) arises when all sites of the antenna are closed under a light saturation flash. Damage to the light harvesting complexes is expressed as a decrease in Fv/Fm. To determine Fo, dark adaptation was performed using dark adaptation clips. These clips were attached to the leaves of five biological replications of cabbages per cultivar for half an hour prior to taking the measurements at midday and allowing emission measurements at a uniform distance while a sliding shutter excluded the light. The light pulse intensity used was $3500 \mu \mathrm{mol} \mathrm{m}^{-2} \mathrm{~s}^{-1}$ for $1 \mathrm{~s}$ [50]. CF transient data were used to perform all of the calculations. The maximum quantum yield (efficiency) of PS II photochemistry $(F v / F m)$ and the performance index $\left(P I_{A B S}\right)$ were then further evaluated and analysed to differentiate the most heat-tolerant and -sensitive cabbage cultivars. $\mathrm{CF}$, the proportion of variable ( $F_{V}$ to maximum fluorescence $\left.F_{M}\right)$, was utilized as an indirect method to measure the damage to the thylakoid membrane [51,52]. To measure thylakoid membrane damage (TMD) caused by HS, the $F_{V} / F_{M}$ values between the control and heat-treated plants were compared. The relative damage was estimated as

$$
\% \mathrm{TMD}=[(\mathrm{Fv} / \mathrm{Fm} \text { control }-\mathrm{Fv} / \mathrm{Fm} \text { heat }) / \mathrm{Fv} / \mathrm{Fm} \text { control }] \times 100 .
$$

\subsection{Cell Membrane Thermostability (CMT) Test}

CMT measurement was conducted according to the procedure demonstrated by Usman et al. (2015). Samples with similar leaf sizes were carefully chosen from different white and red cabbage cultivars under NS (control at $25 \pm 2{ }^{\circ} \mathrm{C}$ ) conditions. A $5 \mathrm{~mm}$ diameter leaf puncher was used to prepare six leaf disks, each approximately $5 \mathrm{~mm}$ in size, consisting of a paired set (control (C) and treatment $(\mathrm{T})$ ). The disks were punched from five biological replications of fully expanded third leaves from each white and red cabbage cultivar and each was replicated three times. Prior to performing the test, to eliminate electrolytes adhering to the leaf discs surface, the paired set of leaf disks were set in two distinct test tubes $(50 \mathrm{~mL})$ and immersed thoroughly with four changes of deionized water (DIW), $10 \mathrm{~mL}$ each time. Then, both sets of test tubes were embedded into $10 \mathrm{~mL}$ of DIW and sealed with aluminium foil to avoid evaporation. Next, test tubes containing the $C$ set were kept at toom temperature. The test tubes containing the treatment set were incubated for $20 \mathrm{~min}$ at $50^{\circ} \mathrm{C}$ in a water bath. Afterwards, both test tubes were kept in the refrigerator. After incubation at $4{ }^{\circ} \mathrm{C}$ for $24 \mathrm{~h}$, the test tubes were allowed to reach to room temperature (RT) and initial conductance readings were carried out for both the TEC 1 and CEC 1 sets using a bench electrical conductivity meter (Starter 3000C; Ohaus Corp., Parsippany, NJ, USA). The tubes were then wrapped once more with aluminium foil and autoclaved for $20 \mathrm{~min}$ at $121^{\circ} \mathrm{C}$ and $0.15 \mathrm{MPa}$ to completely kill the leaf tissue. After autoclaving was accomplished, the tubes wee allowed to cool down to RT and the contents were thoroughly mixed. The reading of the final conductance of TEC 2 and CEC 2 was recorded. The CMT was calculated using following equations:

$$
\operatorname{CMT}(\%)=(1-(\text { TEC } 1 / \text { TEC } 2)) /(1-(\text { CEC } 1 / \text { CEC } 2)) \times 100
$$


where TEC and CEC are the conductance measurements in the treated and control test tubes, respectively, for the initial (CEC 1 and TEC 1) and final (CEC 2 and TEC 2) conductance measurements. Relative injury was also calculated based on the following equation:

$$
\% R I=\{1-[1-(\text { TEC } 1 / \text { TEC } 2)] /[1-(\text { CEC } 1 / \text { CEC } 2)] \times 100\} .
$$

\subsection{Determination of the Morphological Characteristics of Heat-Stressed Brassica oleracea}

The sampling for morphological analysis of all HS-exposed white cabbage cultivars and one red cabbage cultivar was carried out immediately after giving the HS treatment. The effects of HS on growth performance of the cabbage cultivars were assessed based on the ability to form heads as well as the weight, width and length of the heads that formed and the ratios of the obtained measurements. Measurements of the morphological characteristics were taken in five replications (biological replicates).

\subsection{Quantitative Real-Time PCR (qRT-PCR) Analysis}

Total RNA was isolated from leaf tissue using TRIzol (Life Technologies, Invitrogen ${ }^{\mathrm{TM}}$, CA, USA catalog number: 15596018) according to Macrae's protocol [53]. iScript cDNA Synthesis Kit (Bio-Rad Laboratories Inc., Hercules, CA, USA) was used in the in vitro transcription of RNA according to the manufacturers' instructions. RT-qPCR was carried out utilising a Bio-Rad CFX96 real-time device (C1000 Touch thermal cycler) with two primers for each target gene (the list of all primers used in this study is shown in Table A1, Appendix A). For amplification, iTaq Universal SYBR Green supermix (Bio-Rad Laboratories, Inc., Hercules, CA, catalog number: 172-5121) was employed in a final volume of $10 \mu \mathrm{L}$. The cycler was programmed as follows: $95^{\circ} \mathrm{C}$ for $10 \mathrm{~min}$ followed by 40 cycles of $95{ }^{\circ} \mathrm{C}$ for $15 \mathrm{~s}, 60{ }^{\circ} \mathrm{C}$ for $1 \mathrm{~min}$, and then $95^{\circ} \mathrm{C}$ for $15 \mathrm{~s}$. The reference genes used were B. oleracea ubiquitin conjugating enzyme (BoUBC), hypothetical protein (BoUNK1) and actin (BoActin) to normalize the gene expression values. The $\Delta \Delta \mathrm{Cq}$ method was used to determine the difference in relative gene expression of the candidate genes in this study. Assessment in RT-qPCR was performed with three repetitions (technical replicates) of three individual samples (biological replicates) with all the genes in all the treatments.

\subsection{Statistical Analysis}

Statistical analysis was performed using the statistical analysis system (SAS) program (Version 9.2). All values were shown as mean \pm SE (Standard Error); $(n=5)$ represents means for five biological replications per treatment. Data were subjected to one-way analysis of variance (ANOVA) for mean comparison and significant differences were calculated according to Tukey's Studentized Range (HSD) Test. Probability level for all statistical analyses was 0.05 .

\subsection{Drawing Co-Expressed Gene Networks for Query Genes in This Study through GeneMANIA Tools}

The key genes in the HS response network that were used for expression profiling in this study were nominated for the network study in abiotic stress tolerance. In order to depict DPB3-1 regulatory networks and the analysed co-expressed genes, the GeneMANIA (http: / / www.genemania.org accessed August 2019) web tool was used. GeneMANIA is linked to the Arabidopsis model organism database (TAIR) and to the Arabidopsis resource BAR and uses a combination of different datasets to find the genes that are most related to a set of query genes. The combined dataset consists of genetic interactions, pathways, co-expression, co-localization and protein domain similarity. Using this database, an analysis of key genes in HS response interacting with $D P B 3-1$ together with gene function predictions was carried out.

\section{Conclusions}

In conclusion, the results obtained from our physiological data on chlorophyll content and fluorescence, stomatal conductance, cell membrane thermostability and relative 
thylakoid damage together with morphological data on cabbage head formation provided a comprehensive universal morpho-physiological indicator for differentiation of heattolerant and -sensitive populations of B. olearacea cultivars and possibly for other vegetable crops. Our results confirmed that the expression of BoHSP70 can be a universal biomarker for monitoring HS in cabbages, while BoSCL13 expression is helpful to differentiate HTC from HSC for white cabbages. The suppression of BoDPB3-1 expression may reduce selectivity for HS response target genes by DREB2A, resulting in increased sensitivity to HS in HSC red cabbages. Clearly, prior knowledge of cabbage-specific gene expression profiles under HS is essential in applying the gene expression biomarkers based on HS response network.

Supplementary Materials: The following are available online at https:/ /www.mdpi.com/article/10 .3390/plants10061064/s1, Figure S1: Gene interaction network in Arabidopsis for the genes of interest used for the gene expression study in this work. The network was generated by the GeneMANIA prediction server [43]. The right panel presents the different types of interactions with respective color coding, depicted with lines connecting genes in the network: physical interactions (pink), predicted (orange), co-expression (purple) and shared protein domains. Red-filled circles considered heat-shock protein binding.

Author Contributions: M.M. designed and performed the experiments, analyzed the data and wrote the manuscript; S.N.A.A. supervised the project, contributed to the writing and edited the whole article; P.N. co-supervised the project. All authors have read and agreed to the published version of the manuscript.

Funding: This research was funded by the Ministry of Education, Malaysia, grant number FRGS 2013-2.

Institutional Review Board Statement: Not applicable.

Informed Consent Statement: Not applicable.

Data Availability Statement: The data are contained within the article.

Acknowledgments: The authors thank the Department of Agriculture Technology, Faculty of Agriculture, Universiti Putra Malaysia, for the laboratory facilities provided and the financial support in the form of a research grant FRGS 2013-2 from the Ministry of Higher Education Malaysia.

Conflicts of Interest: The authors declare no conflict of interest.

\section{Appendix A}

Table A1. List of primers used in this study.

\begin{tabular}{ccc}
\hline Name & Primer $\mathbf{5}^{\prime}$-3' & Reference \\
\hline UBCF & TTATGAAGGCGGAGTGTTT & {$[54]$} \\
UBCR & TGAACCCTCTCGCATCTC & \\
UNK1F & TTACACACCACAAAGAGAGT & {$[54]$} \\
UNK1R & TACAACACCTGAAACCCATG & \\
ACT F & GAATCCACGAGACAACATAT & {$[54]$} \\
ACT R & AGGGAAGCAAGAATGGAAC & \\
Hsp70 F & GGGAAGGCTGTCCAAGGAAGAG & {$[2]$} \\
Hsp70 R & CCATGCCACCAGCTCCACCCATATC & \\
SCL13 F & CCGAAACTCGTGACGCTAGTGGAGC & {$[2]$} \\
SCL13 R & GCGGAACATGTAGCCATGGGTCTCC & \\
DPB3 F & CGACGAGAGATACGAGTTCC & Designing specific primers \\
DPB3 R & GCTTCTTTCCCATTCCTCCA & \\
DRIP F & TGAAACACGAGAGGAGAAAGG & Designing specific primers \\
DRIP R & TGGAATCTGAGGCAAGGATG & \\
\hline
\end{tabular}


Table A2. List of the B. oleracea cultivars used in this study.

\begin{tabular}{|c|c|c|}
\hline Classification & Source of Seeds & Characteristics \\
\hline \multirow{4}{*}{ White Cabbage } & KAGAYAKI & $\begin{array}{l}\text { Mikado Kyowa seed Round shaped head with } \\
\text { bright green color. Extra early maturity of } 43-48 \\
\text { days, } 1.0-1.3 \mathrm{~kg} \text { in weight. Compact plant with } \\
\text { semi-open, compact outer leaves suitable for density } \\
\text { planting. Tolerant to Cabbage Yellows (B type) and } \\
\text { Black Rot. }\end{array}$ \\
\hline & $\begin{array}{c}\text { P S Hybrid Cabbage } \\
\text { Petoseed }\end{array}$ & $\begin{array}{l}\text { Early maturity tropical type with excellent yield, } \\
\text { uniformity, disease resistance, shippability. } \\
\text { Resistance: yellows, Xanthomonas campestris. }\end{array}$ \\
\hline & Green World Cabbage & $\begin{array}{c}\text { High weather conditions. One round shape and } \\
\text { average weight of } 1.5 \mathrm{~kg}\end{array}$ \\
\hline & $\begin{array}{l}\text { Hybrid Cabbage giant } \\
\text { Takii \& co., LTD Kyoto, } \\
\text { Japan }\end{array}$ & $\begin{array}{l}\text { Hybrid, midseason, Bravo class, denser heads, } \\
\text { bright green. Resistance: yellows; high tolerance to } \\
\text { black rot, tolerance to thrips, tipburn, heat, cold. }\end{array}$ \\
\hline Red Cabbage & $\begin{array}{c}\text { Red Globe } \\
\text { Mikado Kyowa Seed }\end{array}$ & $\begin{array}{c}\text { Hybrid, round shaped head with deep purplish red } \\
\text { color. Medium maturity of } 75 \text { days, } 1.5-2.0 \mathrm{~kg} \text { in } \\
\text { weight. Uniform, compact, short cored head with } \\
\text { thick and tender leaves. Good quality and taste. } \\
\text { Slow bursting. }\end{array}$ \\
\hline
\end{tabular}

\section{References}

1. Cardi, T.; D'Agostino, N.; Tripodi, P. Genetic transformation and genomic resources for next-generation precise genome engineering in vegetable crops. Front. Plant Sci. 2017, 8. [CrossRef]

2. Park, H.J.; Jung, W.Y.; Lee, S.S.; Song, J.H.; Kwon, S.-Y.; Kim, H.; Kim, C.; Ahn, J.C.; Cho, H.S. Use of Heat Stress Responsive Gene Expression Levels for Early Selection of Heat Tolerant Cabbage (Brassica oleracea L.). Int. J. Mol. Sci. 2013, 14, 11871-11894. [CrossRef]

3. Ravanfar, S.A.; Orbovic, V.; Moradpour, M.; Abdul Aziz, M.; Karan, R.; Wallace, S.; Parajuli, S. Improvement of tissue culture, genetic transformation, and applications of biotechnology to Brassica. Biotechnol. Genet. Eng. Rev. 2017, 33, 1-25. [CrossRef] [PubMed]

4. Hasanuzzaman, M.; Nahar, K.; Alam, M.M.; Roychowdhury, R.; Fujita, M. Physiological, biochemical, and molecular mechanisms of heat stress tolerance in plants. Int. J. Mol. Sci. 2013, 14, 9643-9684. [CrossRef] [PubMed]

5. Ahuja, I.; de Vos, R.C.H.; Bones, A.M.; Hall, R.D. Plant molecular stress responses face climate change. Trends Plant Sci. 2010, 15, 664-674. [CrossRef]

6. Mittler, R.; Blumwald, E. Genetic Engineering for Modern Agriculture: Challenges and Perspectives. Annu. Rev. Plant Biol. 2010, 61, 443-462. [CrossRef] [PubMed]

7. Ruelland, E.; Zachowski, A. How plants sense temperature. Environ. Exp. Bot. 2010, 69, 225-232. [CrossRef]

8. Suzuki, N.; Mittler, R. Reactive oxygen species and temperature stresses: A delicate balance between signaling and destruction. Physiol. Plant. 2006, 126, 45-51. [CrossRef]

9. Nurniwalis, A.W.; Suhaimi, N.; Siti Nor Akmar, A.; Aminah, S.; Mohamad Arif, M.A. Gene discovery via expressed sequence tags from the oil palm (elaeis guineensis Jacq.) mesocarp. J. Oil Palm Res. 2008, 87-96.

10. Lin, K.H.; Huang, H.C.; Lin, C.Y. Cloning, expression and physiological analysis of broccoli catalase gene and Chinese cabbage ascorbate peroxidase gene under heat stress. Plant Cell Rep. 2010, 29, 575-593. [CrossRef]

11. Hirsch, S.; Oldroyd, G.E.D. GRAS-domain transcription factors that regulate plant development. Plant Signal. Behav. 2009, 4, 698-700. [CrossRef] [PubMed]

12. Wang, W.; Vinocur, B.; Shoseyov, O.; Altman, A. Role of plant heat-shock proteins and molecular chaperones in the abiotic stress response. Trends Plant Sci. 2004, 9, 244-252. [CrossRef] [PubMed]

13. Bahari, M.N.A.; Sakeh, N.M.; Abdullah, S.N.A.; Ramli, R.R.; Kadkhodaei, S. Transciptome profiling at early infection of Elaeis guineensis by Ganoderma boninense provides novel insights on fungal transition from biotrophic to necrotrophic phase. BMC Plant Biol. 2018, 18. [CrossRef] [PubMed]

14. Ohama, N.; Sato, H.; Shinozaki, K.; Yamaguchi-Shinozaki, K. Transcriptional Regulatory Network of Plant Heat Stress Response. Trends Plant Sci. 2017, 22, 53-65. [CrossRef]

15. Sato, H.; Mizoi, J.; Tanaka, H.; Maruyama, K.; Qin, F.; Osakabe, Y.; Morimoto, K.; Ohori, T.; Kusakabe, K.; Nagata, M.; et al. Arabidopsis DPB3-1, A DREB2A Interactor, Specifically Enhances Heat Stress-Induced Gene Expression by Forming a Heat Stress-Specific Transcriptional Complex with NF-Y Subunitsc w. Plant Cell 2014, 26, 4954-4973. [CrossRef] 
16. Sato, H.; Suzuki, T.; Takahashi, F.; Shinozaki, K.; Yamaguchi-Shinozaki, K. NF-YB2 and NF-YB3 have functionally diverged and differentially induce drought and heat stress-specific genes. Plant Physiol. 2019, 180, 1677-1690. [CrossRef]

17. Sato, H.; Todaka, D.; Kudo, M.; Mizoi, J.; Kidokoro, S.; Zhao, Y.; Shinozaki, K.; Yamaguchi-Shinozaki, K. The Arabidopsis transcriptional regulator DPB3-1 enhances heat stress tolerance without growth retardation in rice. Plant Biotechnol. J. 2016, 14, 1756-1767. [CrossRef]

18. Qin, F.; Sakuma, Y.; Tran, L.S.P.; Maruyama, K.; Kidokoro, S.; Fujita, Y.; Fujita, M.; Umezawa, T.; Sawano, Y.; Miyazono, K.I.; et al. Arabidopsis DREB2A-interacting proteins function as Ring E3 ligases and negatively regulate plant drought stress-responsive gene expression. Plant Cell 2008, 20, 1693-1707. [CrossRef]

19. Ebrahimi, M.; Abdullah, S.N.A.; Abdul Aziz, M.; Namasivayam, P. Oil palm EgCBF3 conferred stress tolerance in transgenic tomato plants through modulation of the ethylene signaling pathway. J. Plant Physiol. 2016, 202, 107-120. [CrossRef]

20. Yuan, Y.; Fang, L.; Karungo, S.K.; Zhang, L.; Gao, Y.; Li, S.; Xin, H. Overexpression of VaPAT1, a GRAS transcription factor from Vitis amurensis, confers abiotic stress tolerance in Arabidopsis. Plant Cell Rep. 2016, 35, 655-666. [CrossRef] [PubMed]

21. Torres-Galea, P.; Huang, L.F.; Chua, N.H.; Bolle, C. The GRAS protein SCL13 is a positive regulator of phytochrome-dependent red light signaling, but can also modulate phytochrome A responses. Mol. Genet. Genom. 2006, 276, 13-30. [CrossRef] [PubMed]

22. Urban, J.; Ingwers, M.W.; McGuire, M.A.; Teskey, R.O. Increase in leaf temperature opens stomata and decouples net photosynthesis from stomatal conductance in Pinus taeda and Populus deltoides x nigra. J. Exp. Bot. 2017, 68, 1757-1767. [CrossRef] [PubMed]

23. Nyarko, G.; Alderson, P.G.; Craigon, J.; Murchie, E.; Sparkes, D.L. Comparison of cell membrane thermostability and chlorophyll fluorescence parameters for the determination of heat tolerance in ten cabbage lines. J. Horticult. Sci. Biotechnol. 2008, 83, 678-682. [CrossRef]

24. Crafts-Brandner, S.J.; Salvucci, M.E. Sensitivity of photosynthesis in a C4 plant, maize, to heat stress. Plant Physiol. 2002, 129, 1773-1780. [CrossRef] [PubMed]

25. Haworth, M.; Marino, G.; Brunetti, C.; Killi, D.; De Carlo, A.; Centritto, M. The impact of heat stress and water deficit on the photosynthetic and stomatal physiology of olive (Olea europaea L.) - A case study of the 2017 heat wave. Plants 2018, 7, 76. [CrossRef] [PubMed]

26. Azzeme, A.M.; Abdullah, S.N.A.; Aziz, M.A.; Wahab, P.E.M. Oil palm leaves and roots differ in physiological response, antioxidant enzyme activities and expression of stress-responsive genes upon exposure to drought stress. Acta Physiol. Plant. 2016, $38,1-12$. [CrossRef]

27. Kuo, C.G.; Shen, B.J.; Chen, H.M.; Chen, H.C.; Opeña, R.T. Associations between heat tolerance, water consumption, and morphological characters in Chinese cabbage. Euphytica 1988, 39, 65-73. [CrossRef]

28. Hu, S.; Ding, Y.; Zhu, C. Sensitivity and Responses of Chloroplasts to Heat Stress in Plants. Front. Plant Sci. 2020, 11, 1-11. [CrossRef]

29. Marchand, F.L.; Mertens, S.; Kockelbergh, F.; Beyens, L.; Nijs, I. Performance of High Arctic tundra plants improved during but deteriorated after exposure to a simulated extreme temperature event. Glob. Chang. Biol. 2005, 11, 2078-2089. [CrossRef]

30. Wang, J.Z.; Cui, L.J.; Wang, Y.; Li, J.L. Growth, lipid peroxidation and photosynthesis in two tall fescue cultivars differing in heat tolerance. Biol. Plant. 2009, 53, 237-242. [CrossRef]

31. Ashraf, M.; Hafeez, M. Thermotolerance of pearl millet and maize at early growth stages: Growth and nutrient relations. Biol. Plant. 2004, 48, 81-86. [CrossRef]

32. Rodríguez, M.; Canales, E.; Borrás-Hidalgo, O. Molecular aspects of abiotic stress in plants. Biotecnol. Aplic. 2005, 22, 1-10.

33. Morales, D.; Rodríguez, P.; Dell'Amico, J.; Nicolás, E.; Torrecillas, A.; Sánchez-Blanco, M.J. High-temperature preconditioning and thermal shock imposition affects water relations, gas exchange and root hydraulic conductivity in tomato. Biol. Plant. 2003, 47, 203-208. [CrossRef]

34. Wang, Q.L.; Chen, J.H.; He, N.Y.; Guo, F.Q. Metabolic reprogramming in chloroplasts under heat stress in plants. Int. J. Mol. Sci. 2018, 19, 849. [CrossRef] [PubMed]

35. Porcar-Castell, A.; Tyystjärvi, E.; Atherton, J.; Van Der Tol, C.; Flexas, J.; Pfündel, E.E.; Moreno, J.; Frankenberg, C.; Berry, J.A. Linking chlorophyll a fluorescence to photosynthesis for remote sensing applications: Mechanisms and challenges. J. Exp. Bot. 2014, 65, 4065-4095. [CrossRef]

36. Tan, W.; Meng, Q.W.; Brestic, M.; Olsovska, K.; Yang, X. Photosynthesis is improved by exogenous calcium in heat-stressed tobacco plants. J. Plant Physiol. 2011, 168, 2063-2071. [CrossRef]

37. Maxwell, K.; Johnson, G.N. Chlorophyll fluorescence-A practical guide. J. Exp. Bot. 2000, 51, 659-668. [CrossRef]

38. Craufurd, P.Q.; Prasad, P.V.V.; Kakani, V.G.; Wheeler, T.R.; Nigam, S.N. Heat tolerance in groundnut. Field Crop. Res. 2003, 80, 63-77. [CrossRef]

39. Agarie, S.; Hanaoka, N.; Kubota, F.; Agata, W.; Kaufman, P. Measurement of Cell Membrane Stability Evaluated by Electrolyte Leakage as a Drought and Heat Tolerance Test in Rice (Oryza sativa L.). J. Fac. Agric. Kyushu Univ. 1995, 40, 233-240. [CrossRef]

40. Usman, M.G.; Rafii, M.Y.; Ismail, M.R.; Malek, M.A.; Latif, M.A. Expression of Target Gene HSP70 and Membrane Stability Determine Heat Tolerance in chili pepper. J. Am. Soc. Horticult. Sci. 2015, 140, 144-150. [CrossRef]

41. Warde-Farley, D.; Donaldson, S.L.; Comes, O.; Zuberi, K.; Badrawi, R.; Chao, P.; Franz, M.; Grouios, C.; Kazi, F.; Lopes, C.T.; et al. The GeneMANIA prediction server: Biological network integration for gene prioritization and predicting gene function. Nucl. Acids Res. 2010, 38, 214-220. [CrossRef] [PubMed] 
42. Sabaghian, E.; Drebert, Z.; Inze, D.; Saeys, Y. An integrated network of Arabidopsis growth regulators and its use for gene prioritization. Sci. Rep. 2015, 5, 1-13. [CrossRef]

43. Yuan, Y.; Chiu, L.W.; Li, L. Transcriptional regulation of anthocyanin biosynthesis in red cabbage. Planta 2009, 230, 1141-1153. [CrossRef]

44. Wang, Z.; Cui, Y.; Vainstein, A.; Chen, S.; Ma, H. Regulation of fig (Ficus carica L.) fruit color: Metabolomic and transcriptomic analyses of the flavonoid biosynthetic pathway. Front. Plant Sci. 2017, 8. [CrossRef] [PubMed]

45. Kim, J.S.; Mizoi, J.; Yoshida, T.; Fujita, Y.; Nakajima, J.; Ohori, T.; Todaka, D.; Nakashima, K.; Hirayama, T.; Shinozaki, K.; et al. An ABRE promoter sequence is involved in osmotic stress-responsive expression of the DREB2A gene, which encodes a transcription factor regulating drought-inducible genes in Arabidopsis. Plant Cell Physiol. 2011, 52, 2136-2146. [CrossRef] [PubMed]

46. Sakuma, Y.; Maruyama, K.; Qin, F.; Osakabe, Y.; Shinozaki, K.; Yamaguchi-Shinozaki, K. Dual function of an Arabidopsis transcription factor DREB2A in water-stress-responsive and heat-stress-responsive gene expression. Proc. Natl. Acad. Sci. USA 2006, 103, 18822-18827. [CrossRef] [PubMed]

47. Hyun, J.A.; Jin, S.B.; Byoung, C.K.; Hyo, G.P. Production of somatic hybrids between satsuma mandarin (Citrus unshiu) and navel orange (Citrus sinensis) by protoplast fusion. J. Plant Biol. 2008, 51, 186-191. [CrossRef]

48. Moradpour, M.; Abdulah, S.N.A. CRISPR/dCas9 platforms in plants: Strategies and applications beyond genome editing. Plant Biotechnol. J. 2020, 18, 32-44. [CrossRef]

49. Arsenault, E.A.; Yoneda, Y.; Fleming, G.R.; Niyogi, K.K. The role of mixed vibronic Qy-Qx states in green light absorption of light-harvesting complex II. Nat. Commun. 2020, 1-9. [CrossRef]

50. Molina-Bravo, R.; Arellano, C.; Sosinski, B.R.; Fernandez, G.E. A protocol to assess heat tolerance in a segregating population of raspberry using chlorophyll fluorescence. Sci. Horticult. 2011, 130, 524-530. [CrossRef]

51. Kadir, S.; Von Weihe, M.; Al-Khatib, K. Photochemical efficiency and recovery of photosystem II in grapes after exposure to sudden and gradual heat stress. J. Am. Soc. Horticult. Sci. 2007, 132, 764-769. [CrossRef]

52. Thomason, K.; Babar, M.A.; Erickson, J.E.; Mulvaney, M.; Beecher, C.; MacDonald, G. Comparative physiological and metabolomics analysis of wheat (Triticum aestivum L.) following post-anthesis heat stress. PLoS ONE 2018, 13, e0197919. [CrossRef] [PubMed]

53. MacRae, E. Extraction of plant RNA. Methods Mol. Biol. 2007, 353, 15-24. [CrossRef] [PubMed]

54. Sheng, X.G.; Zhao, Z.Q.; Yu, H.F.; Wang, J.S.; Zheng, C.F.; Gu, H.H. In-depth analysis of internal control genes for quantitative real-time PCR in Brassica oleracea var. botrytis. Genet. Mol. Res. 2016, 15. [CrossRef] [PubMed] 